\title{
ATELLÂ \\ No caminho da poética geográfica: experiência e imaginação do patrimônio
}

\author{
On the path of poetic geography: heritage experience and \\ imagination
}

\section{En el camino de la poética geográfica: experiencia e imaginación del patrimonio}

\author{
Rafael Henrique Teixeira da Silva \\ Universidade Federal de Juiz de Fora \\ rafahts@hotmail.com
}

\begin{abstract}
Resumo
No presente artigo pretendemos, a partir da experiência enquanto escala epistemológica, caminhar no sentido da busca pelas manifestações do patrimônio no espaço geográfico de São Cristóvão-SE. Fomos à procura do patrimônio revelado nas geograficidades, na cumplicidade do homem com a Terra, nessa relação intrínseca que aflora no correr mundo adentro. Nesse sentido, nosso objetivo é buscar apreender o patrimônio de São Cristóvão por meio de itinerários geográficos e poéticos resultados de diversas caminhadas e trajetos realizados pela cidade. A partir da fenomenologia poética bachelardiana e da realização e descrição de experiências pessoais e coletivas, almeja-se vislumbrar novas possibilidades epistemológicas e metodológicas na geografia. A composição das experiências consideradas no presente artigo constitui-se de nossas vivências, de relatos da população local e de imersões na literatura e outras expressões artísticas de São Cristóvão. Nesse sentido, visamos as ações individuais ou coletivas do ser humano - sobre si e sobre o mundo - nas quais o mesmo adquire consciência de sua existência.

Palavras-chave: Geograficidade; Itinerário Geográfico; Fenomenologia.
\end{abstract}

Abstract

In the present article we intend, from the experience as an epistemological scale, to move towards the search for the manifestations of heritage in the geographic space of São Cristóvão-SE. We searched for the heritage revealed in the geographicities, uncovered in the man's complicity with the Earth, in that intrinsic relation that appears while crossing of the world. In this sense, our objective is to apprehend the heritage of São Cristóvão through geographical and poetic itineraries as an outcome of several walks and routes carried out by the city. From the bachelardian phenomenological perspective and the realization and description of personal and collective experiences, it is hoped to glimpse new epistemological and methodological possibilities in geography. The compositions of the experiences 
considered in this article are based on our experiences, narratives of the local population and immersions in literature and other artistic expressions of São Cristóvão. In this sense, we aim at the individual or collective actions of the human being - about himself and about the world - in which he becomes aware of his existence.

Keywords: Geographicity; Geographical itinerary; Phenomenology.

Resumen

En el presente artículo pretendemos, a partir de la experiencia como escala epistemológica, caminar en el sentido de la búsqueda por las manifestaciones del patrimonio en el espacio geográfico de São Cristóvão-SE. Fuimos a buscar el patrimonio revelado en las geograficidades, en la complicidad del hombre con la Tierra, en esa relación intrínseca que aflora en el correr mundo adentro. En ese sentido, nuestro objetivo es buscar aprehender el patrimonio de São Cristóvão por medio de itinerarios geográficos y poéticos resultados de diversas caminatas y trayectos realizados por la ciudad. A partir de la fenomenología poética bachelardiana y de la realización y descripción de experiencias personales y colectivas, se busca confeccionar nuevas posibilidades epistemológicas y metodológicas en la geografía. La composición de las experiencias consideradas en el presente artículo se constituye de nuestras vivencias, de relatos de la población local y de inmersiones en la literatura y otras expresiones artísticas de São Cristóvão. En ese sentido, visamos las acciones individuales o colectivas del ser humano - sobre sí y sobre el mundo - en las que el mismo adquiere conciencia de su existencia.

Palabras Clave: Geograficidad; Itinerario Geográfico; Fenomenología.

\section{Introdução}

No presente artigo pretendemos, a partir da experiência enquanto escala epistemológica (MARANDOLA JR, 2016), caminhar no sentido da busca pelas manifestações do patrimônio no espaço geográfico de São Cristóvão-SE. Fomos à procura do patrimônio revelado nas geograficidades, na cumplicidade do homem com a Terra (DARDEL, 2011), nessa relação intrínseca que aflora no correr mundo adentro. Nesse sentido, nosso objetivo é buscar apreender o patrimônio de São Cristóvão por meio de itinerários geográficos e poéticos resultados de diversas caminhadas e trajetos realizados pela cidade. A partir da fenomenologia poética bachelardiana e da realização e descrição de experiências pessoais e coletivas, almeja-se vislumbrar novas possibilidades epistemológicas e metodológicas na geografia.

A composição das experiências consideradas no presente artigo constitui-se de nossas vivências, de relatos da população $\operatorname{local}^{1} \mathrm{e}$ de imersões na literatura e outras expressões artísticas (VAN MANEN, 1990) de São Cristóvão. Nesse sentido, visamos as ações individuais ou coletivas do ser humano - sobre si e sobre o mundo - nas quais o mesmo adquire consciência de sua existência (JASPERS, 1965).

A geografia enquanto existência e realidade humana, como nos mostra Dardel (2011), parte da necessidade de compreender o mundo geograficamente. Uma geografia

\footnotetext{
${ }^{1}$ Os relatos mencionados são compostos por conversas informais com moradores de São Cristóvão e entrevistas realizadas tanto com residentes quanto com atores sociais e agentes públicos.
} 
em ato, como vontade de percorrer, desbravar, explorar. Antecedente à ciência objetiva, é uma inquietude por revelações telúricas sobre a condição e o destino humano. A partir duma experiência primitiva, carregada de profundidade e espessura, ultrapassaremos rumo ao mundo irreal, rumo à geografia dos sonhos (DARDEL, 2011; BACHELARD, 2013), em direção a perspectivas geográficas renovadas, buscando novos horizontes e lugares antes inacessíveis (GRATÃO, 2016).

A realidade geográfica é uma noção fundamental da vida humana na Terra, ela revela dimensões do ser do homem (BESSE, 2014a). Nessa geografia primordial é manifesta uma coexistência, uma presença conjunta do homem com a Terra, que caminha nos dois sentidos. Porém, tais relações telúricas não restringem as possibilidades humanas somente a um lugar ou território específico, pelo contrário, configuram uma liberdade que ocorre na travessia dos lugares. Ou melhor, são deslocamentos pelo espaço, um desenraizamento, uma abertura "entre um aqui e um ali" (BESSE, 2014a). Como veremos adiante, essa perspectiva ajudou a fundamentar o que nomeamos como itinerários geográficos.

O saber geográfico - movimento que joga luz sobre a presença contígua homem-Terra e que dá origem a uma emoção - é latente na transferência de valores apreendidos na espacialidade da existência humana. Esse conhecimento, essa "verdade"2 geográfica, vai muito além da submissão desses valores a uma única noção ou a um único conceito geográfico (BESSE, 2011).

Com a pretensão de seguir neste caminho, assumimos que o fenômeno patrimonial não se circunscreve em apenas uma categoria geográfica. Visto que essas categorias insinuam valorizações multifacetadas, foi empreendido um esforço para não se limitar às concepções clássicas e restritivas destas, demonstrando que elas podem suscitar valores opostos.

Nesse entremear, procuramos partir de alguns valores atribuídos à experiência telúrica e não da delimitação a priori das categorias a serem abordadas. Tais valores fornecem um ponto de partida por serem transversais aos espaços, lugares, paisagens, territórios. Assim, reforçamos nossa ruptura com um cesarismo, desviando de determinações orgânicas.

$\mathrm{Na}$ esteira do pensamento de autores como Sheller e Urry (2006), Hein et al. (2008) e Novoa (2015), pode-se aprofundar - epistemologicamente e metodologicamente - de modo coerente com as ideias aqui transpostas. Recentemente, alguns geógrafos têm repensado o papel da esfera teórico-metodológica, o que vem aspirando um frescor de novidade por meio da criação de métodos contemporâneos (DOWLING et al., 2016; DOWLING et al., 2016b). Tais perspectivas consideram as práticas habituais, as relações que ocorrem nos pontos de encontro, as redes de amizade,

\footnotetext{
2 Acredita-se que o sentido da palavra "verdade" utilizada por Besse (2011) estaria próximo ao de Jaspers (1965, p. 140), de verdade em movimento contínuo que transcorre interminavelmente, uma batalha perpétua que decididamente não está em repouso, não é imóvel.
} 
os espaços de ócio, buscando ir além de uma leitura pragmática (PRATS FERRET et al., 2012).

Nessa perspectiva, com início em diferentes campos das ciências sociais, os métodos móveis ${ }^{3}$ - que surgiram há alguns anos e afetaram também os trabalhos realizados na geografia (SHELLER E URRY, 2006; MERRIMAN, 2014; SPINNEY, 2015), - são uma porta de entrada para uma metodologia flexível.

Tal plasticidade existe tanto na acepção da não (pré)definição de metodologias sectárias, quanto no entendimento que o mundo só é cognoscível ao percorrê-lo, ao atravessá-lo. Nessa senda, o ato de caminhar pode ser compreendido como um elemento que auxilia a forjar entendimentos sobre lugar, paisagem, território (WYLIE, 2006). Um ato que arrisca, suspeita, transgride (CERTEAU, 1994). É um relance a respeito das formas como as pessoas compreendem o mundo e, ainda mais, sobre os valores que surgem dessas relações telúricas.

$\mathrm{Na}$ vereda perene pela essência do patrimônio, procuramos desvelar a construção das ligações concretas e afetivas que os sancristovenses possuem com a Terra. O patrimônio, enquanto elemento fundamental nas geograficidades, manifesta-se como um excesso de vida, uma grande lareira de obras e ações indisciplinadas. Ele não pode ser resolvido em conceito, antes deve ser imaginado e experienciado. $\mathrm{O}$ comprometimento em tentar compreender essas experiências nos lançou na ambiciosa tentativa de propor itinerários geográficos possíveis.

\section{A construção de itinerâncias metodológicas}

Por itinerários geográficos entendemos a indicação ou o projeto de percurso a seguir e o respectivo esboço de experiências reais e imaginadas, pessoais e coletivas, que compõem os trajetos apresentados. É uma abertura ao mundo que nos arrebata e nos transporta. Numa tensão entre si e o mundo, os itinerários geográficos podem ser imanência, imersão, participação. Uma arte ${ }^{4}$ que se faz num caminhar interrogativo e questionador, que requalifica o espaço. Visa extrapolar uma "excursão geográfica" (MARANDOLA JR e PAULA, 2007), é uma vivência do mundo e de seus valores que além de revelar, constrói (BESSE, 2014b). O itinerário aqui descrito não foi préestabelecidos ao longo de nossas andanças pela cidade, mas surgiu num momento simultâneo de reflexão e transcrição para o papel das vivências em São Cristóvão.

Para compreendermos o patrimônio como fenômeno dinâmico, os itinerários geográficos são pedra angular em uma instrução, por meio de uma construção (BACHELARD, 1988b). Fundados no ato de conversar, caminhar, participar, ou seja, de atravessar e ser atravessado por São Cristóvão, os itinerários geográficos são uma astúcia de aquisição (BACHELARD, 2006; RICOEUR, 2007), procuram ir além da

\footnotetext{
${ }^{3}$ Tradução nossa. Em inglês é mencionada como: mobile methods ou mobile methodologies.

${ }^{4}$ Alguns artistas como Richar Long e Hamish Fulton acreditam que caminhar é fazer obra de arte. Para eles o deslocamento pelo espaço dá origem a criações artísticas (BESSE, 2014b, p. 54).
} 
contemplação, procuram "participar do devenir ardente de uma violência criadora" (BACHELARD, 1985, p. 45).

Desse modo, valores de afetividade e interioridade, intrinsecamente associados à geograficidade (DARDEL, 2011), guiaram nossa imaginação no momento da concepção ortográfica. Em cada instante que era criada uma imagem (PAIVA, 2005) sobre esses valores, ela emancipava-se de causalidades obsoletas, abrindo-se para novos conteúdos. Assim, colocados antes como uma colmeia de sentidos, tais valores proporcionam uma capacidade de maravilhamento, capacidade de ouvirmos as vozes da Terra, vozes ásperas, cavernosas e trovejantes (BACHELARD, 2003).

Por último, devemos ressaltar que nossa escrita foi regada à degustação de livros de poesia. Nesse sentido, a linguagem poética adentra o texto em momentos específicos em que o movimento é realizado rumo ao aprofundamento em vez da objetivação. O linguajar poético caminha no sentido da profundidade e riqueza de que a escrita positiva carece. Utilizamos palavras que procuram desvelar uma verdade que se encontra praticamente fora de nosso alcance (VAN MANEN, 2006), por detrás da razão e do pensamento. Com isso, buscamos trazer as contribuições do leitor para as questões abordadas, numa forma poética da heurística.

\section{Como e onde tudo começou - Estado: Sergipe; Cidade: São Cristóvão.}

Situado na porção leste do Nordeste brasileiro, o Estado de Sergipe (Figura 01) possui uma área de $22.050 \mathrm{~km}^{2}$, limitando-se ao norte com Alagoas, ao sul e oeste com a Bahia e ao leste com o Oceano Atlântico. Ele surgiu para nós, no primeiro momento, como uma oportunidade de realizar o mestrado na Universidade Federal de Sergipe, o que não foi concretizado. À época, a preferência ainda era pela Antropologia, o que mudaria ao percorrer os terrenos baixos e as várzeas do litoral de Sergipe. Não chegamos a conhecer as planícies do norte sergipano, nem o planalto semiárido da região noroeste. Eles foram apreendidos somente pela leitura de textos e pelas imagens dos livros.

Foi no ano de 2010, em Aracaju, que fomos envolvidos pelo clima tropical e as altas temperaturas que permanecem praticamente ao longo de todo ano. $\mathrm{O}$ despertar geográfico veio por meio da experiência sensível de Sergipe enquanto espaço aberto (BESSE, 2014a). Se no primeiro encontro entramos em contato com as bacias do Rio Sergipe e do Rio Vaza-barris, não deixamos de sonhar com as composições hidrográficas do Rio Real, do Rio Japaratuba, do Rio Piauí e, principalmente, do Rio São Francisco. Não apenas por ser a bacia hidrográfica mais importante do estado, mas pelos meses que passamos conhecendo todo seu percurso, de Pirapora a Bom Jesus da Lapa, de Xique-Xique a Piaçabuçu. 


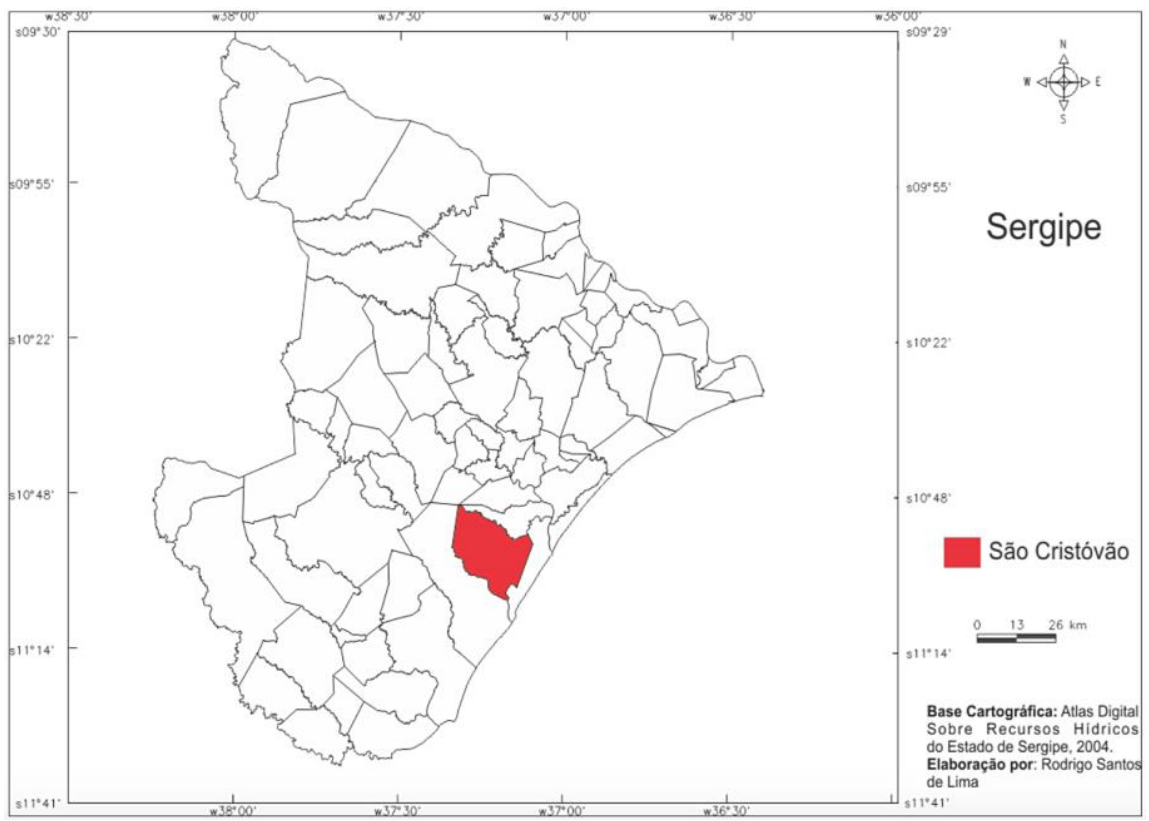

Figura 01: Localização do Município de São Cristóvão-Sergipe.

Fonte: Atlas Digital sobre os Recursos Hídricos do Estado de Sergipe, 2011.

Numa exposição poética do São Francisco ${ }^{5}$, viajamos pelo seu curso d'água conhecendo histórias de pescadores e caixeiros-viajantes, lendas da Mãe d'água e da Pisadeira, sentindo a preocupação, nos relatos, com a construção de barragens e o processo de salinização que afeta populações próximas ao desague do rio. A exposição foi uma anunciação profética de nosso destino, depois dela Sergipe não sairia mais de nossas vidas.

O menor estado da federação possui uma população pequena, de aproximadamente dois milhões de habitantes, porém riquezas imensuráveis. A predominância da população urbana levou a concentração de metade da população na região metropolitana de Aracaju ${ }^{6}$. Apesar disso, a cidade ainda possui características interioranas, de receptividade, proximidade, consideração.

Barra dos Coqueiros, Nossa Senhora do Socorro e São Cristóvão compõem a região metropolitana, e foi a partir do contato com a última que nosso interesse foi despertado. Localizada próxima da capital, São Cristóvão (Figura 02) é reconhecida por

\footnotetext{
${ }^{5}$ No primeiro semestre de 2011 o autor trabalhou como monitor na Exposição "Rio São Francisco Navegado por Ronaldo Fraga: Cultura Popular, Moda e História", que ocorreu no Pavilhão das Culturas Brasileiras (Parque do Ibirapuera - São Paulo/SP).

6 IBGE. Instituto Brasileiro de Geografía e Estatística. Cidades, 2016. [online]. Disponível em: <www.cidades.ibge.gov.br/>, Acesso em: 10 de maio de 2016.
} 
seus monumentos históricos, apesar de seus belíssimos patrimônios transcenderem a tangibilidade.

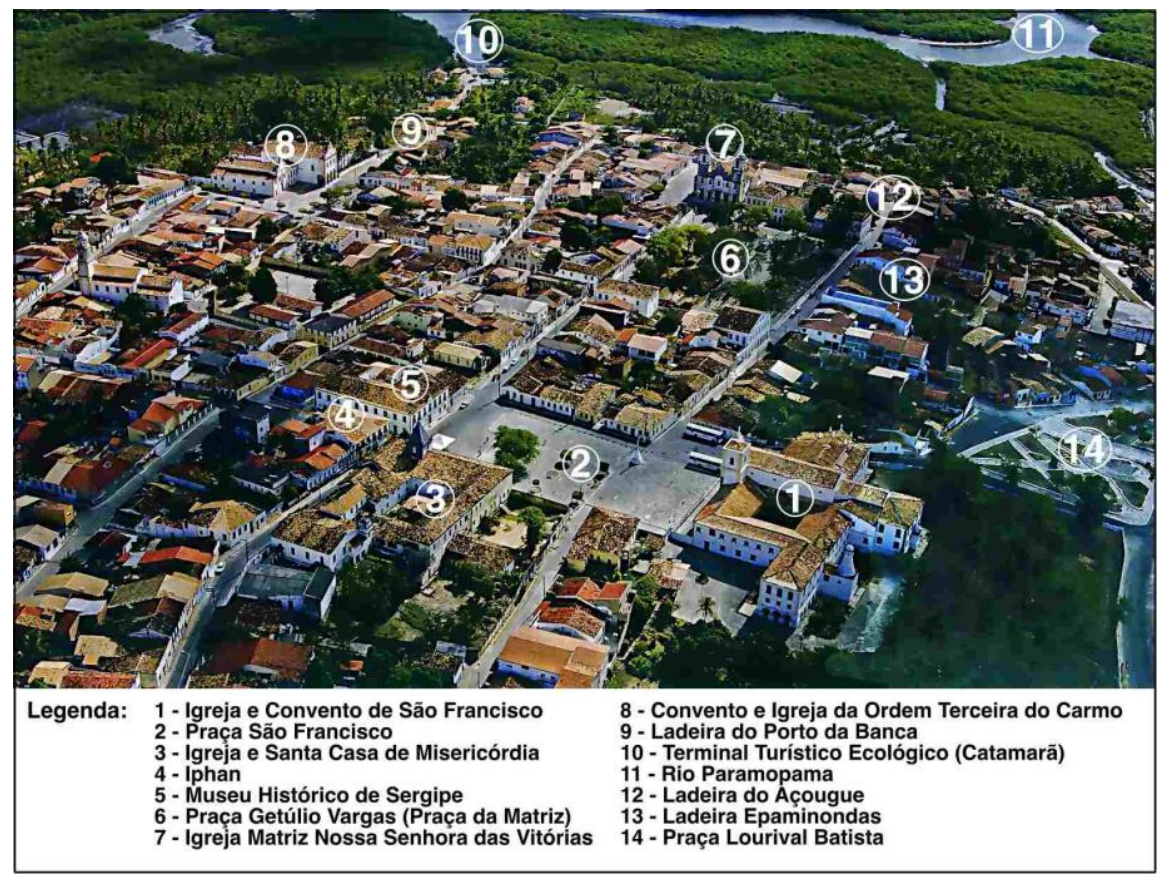

Figura 02: Vista aérea de São Cristóvão-Sergipe

Fonte: GOVERNO DE SERGIPE, 2006, p. 15.; Elaboração: TEIXEIRA DA SILVA, 2018.

Assentada sobre uma colina $20 \mathrm{~km}$ acima da enseada do Rio Vaza-Barris, a antiga capital do estado está situada a $25 \mathrm{~km}$ de Aracaju. Atualmente, a cidade conta com uma população estimada de 87 mil habitantes $^{7}$, que não correspondem com a vida pacata vivenciada nos arredores do centro histórico. Entre fragmentos da mata atlântica e manguezais, procuramos conhecer a cidade e seus patrimônios a partir do chão. Algumas leituras foram fundamentais para estabelecer um ponto de partida, mas somente conhecemos suas densidades por meio do contato direto com pessoas, ruas e esquinas.

\section{Esboço de um itinerário possível: São Cristóvão, cidade poesia}

Ao caminhar pela cidade de São Cristóvão, lugares, territórios e paisagens apresentam-se carregados de ternura, afetividade e intimidade. Se existe alguma verdade no enunciado - e acreditamos que haja - devemos usufruir, despender, deleitar o maior tempo possível na cidade. Enquanto outras localidades suscitam sentimentos de

7 IBGE. Instituto Brasileiro de Geografía e Estatística. Cidades, 2016. [online]. Disponível em: <www.cidades.ibge.gov.br/>, Acesso em: 10 de maio de 2016. 
exclusão, São Cristóvão aparece para nós, neste momento, como um germe da felicidade (BACHELARD, 1988a). A cidade possui valores de concha, valores de ninho (BACHELARD, 1988a), o lugar de uma proteção sólida que desperta em nós uma primitividade em que o habitar é algo natural. Penetramos, assim, os devaneios cósmicos que nos ligam ao nosso mundo e que pertencem à nossa alma (BACHELARD, 2009).

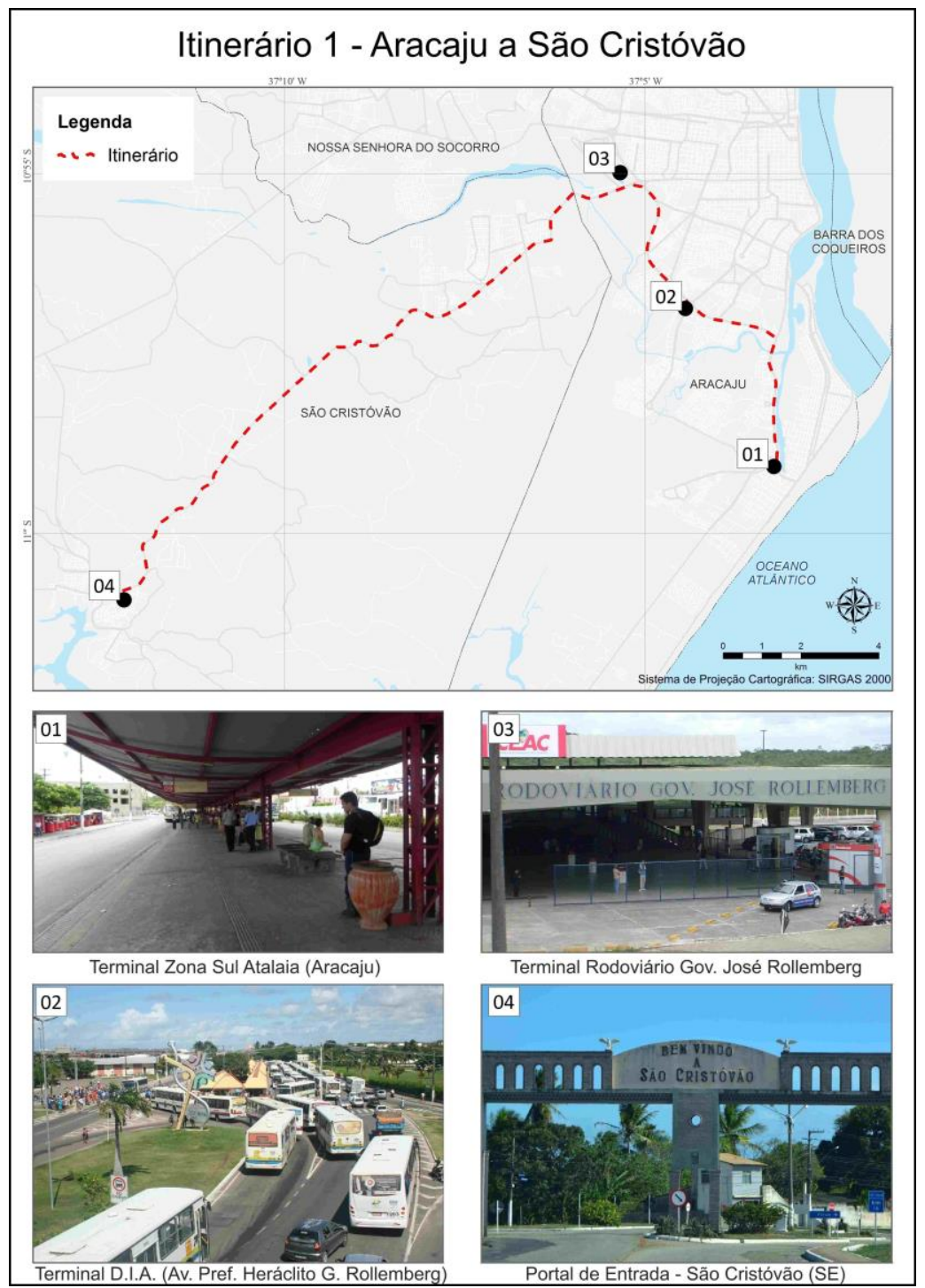

Figura 03: Itinerário de Aracaju a São Cristóvão.

Organização: TEIXEIRA DA SILVA, 2018; Elaboração: Leandro Cardoso. 
Sob uma luz dourada que ilumina a vida temos nosso primeiro contato com São Cristóvão. Neste momento - ainda no ano de 2010 e recém-formados - a angústia oblíqua gerada pela incerteza da incursão na vida acadêmica é esquecida. Enquanto aguardávamos o resultado do processo seletivo de mestrado em Antropologia da UFS, decidimos ir ao encontro da "cidade mãe". Partindo do terminal da Atalaia em Aracaju, continuamos a saga para São Cristóvão (Figura 03). Entre uma parada para troca de ônibus no terminal D.I.A e outra na rodoviária, finalmente estamos na João Bebe Água (Rodovia que liga Aracaju à São Cristóvão). A ligeireza do ônibus e a estrada esburacada dão calafrios.

Ainda na estrada recebemos as boas-vindas do Cristo (Figura 04), que surge no alto da colina São Gonçalo em meio a duas torres de telecomunicação. No portal da cidade já somos tomados por uma vontade de noite, de repouso confortante.

Casas. Casadas lado a lado, as primeiras habitações são um convite à estada. À medida que adentramos seus interiores, nos deparamos com marisqueiras e operários, que antes de tudo são brincantes. Caímos lentamente nos braços da cidade e quando nos damos conta um sentimento rompe o silêncio. Já não somos estranhos ao lugar, essas paisagens estão agora em nós enraizadas, nos sentimos parte deste território, desta fraternidade telúrica. Nosso ser interior entrevê o outro, como uma última tarde de verão.

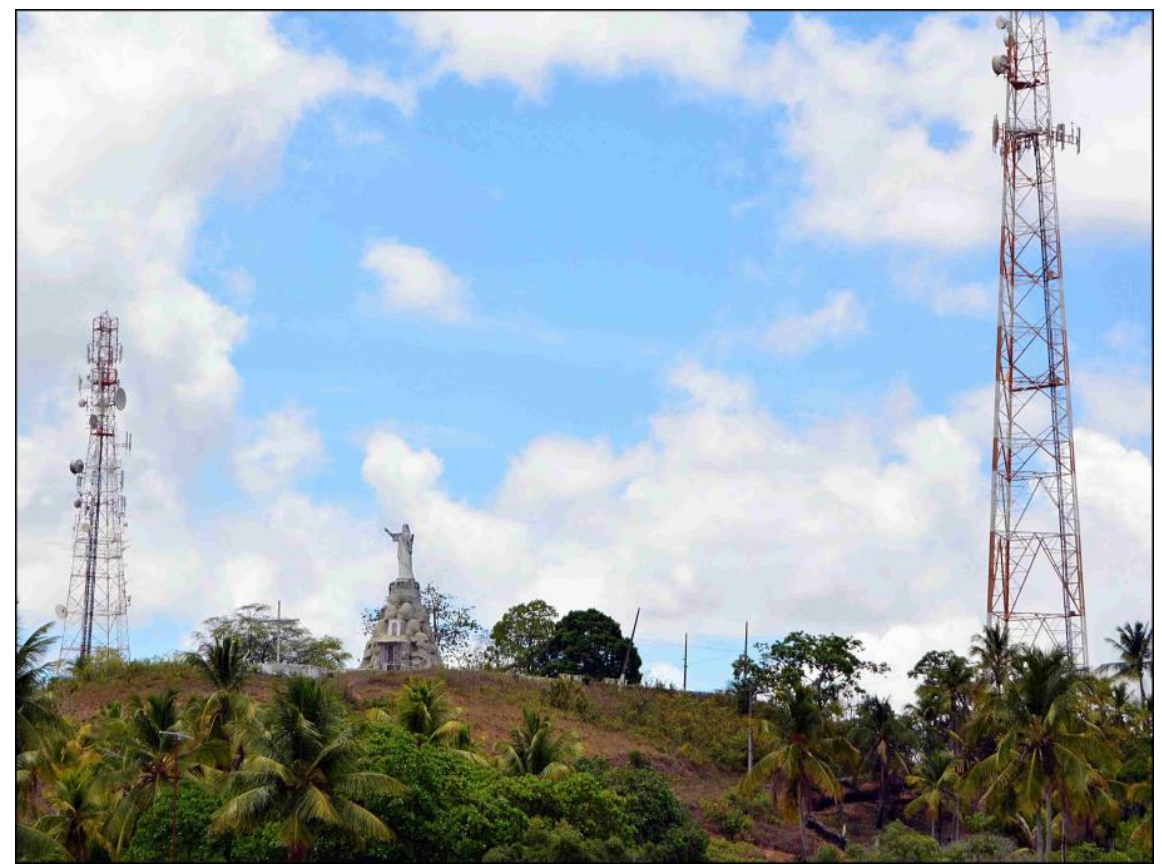

Figura 04: Cristo na entrada de São Cristóvão Fonte: TEIXEIRA DA SILVA, 2018. 
Às vezes, a presença em um lugar novo pode parecer tão familiar quanto a terra natal, onde tudo é acolhimento. Nesse primeiro contato com São Cristóvão nossa rota foi reassumida, ali viramos bruscamente uma página. Abandonamos as digressões socioantropológicas de outrora e fomos tomados por uma embriaguez geográfica. Entregues à tranquilidade que une sonhador e mundo - possibilitando o devaneio anteperceptivo (BACHELARD, 2009) -, fomos arrebatados inteiramente pelo que acabara de nos encantar. Num dentro que não tem fora, vivenciamos a cidade em todo seu volume.

Em São Cristóvão dialogamos com um vocabulário da terra: o rochoso, o luminoso, o líquido, o aéreo, trouxeram à tona uma geografia íntima. Foi a origem de um duplo nascimento, de um despertar para o mundo. Fomos recebidos com um semblante amável pela mãe de Sergipe, onde belezas singulares surgem aos nossos sentidos. Nela encontramos janelas entreabertas para uma ontologia do patrimônio. Um conhecimento que somente seria possível pelo movimento, por meio de itinerários através do espaço. Nesse sentido, sentimos a ânsia de seguir com nossos itinerários geográficos, compostos principalmente pelo ato de caminhar, mas também se utilizando de outros meios de transportes disponíveis.

\section{Últimas palavras}

$\mathrm{Na}$ tentativa de apreender o patrimônio revelado nas geograficidades, nós encontramos um patrimônio rico e dinâmico em São Cristóvão. A partir de um engajamento físico e corporal o patrimônio se revela obra viva e vibrante. Se a quintessência patrimonial funda-se na imaginação e na vontade, o que proporcionou tal abertura e liberdade foram nossos itinerários geográficos.

Trajetos, categorias e conceitos não foram pré-definidos e acolhidos de modo inquestionado. O itinerário geográfico, enquanto orientação, não é um procedimento de verificação, mas uma astúcia de aquisição, um expediente renovado que se interpõe na fronteira entre a experiência e o devaneio. Tal empreendimento solicita uma forma de escrita poética e ensaística não muito comum nos trabalhos acadêmicos.

Com a aspiração de estabelecer novos parâmetros, nossos itinerários foram colocados antes do método e depois da doutrina. Podem ser adaptados para outras buscas que necessitam ser vivenciadas no movimento, na travessia. Porém não possui uma universalidade ou estabilidade aplicável a qualquer temática. Acreditamos que cada trabalho deva desenvolver seus próprios critérios, seus procedimentos peculiares. Apesar de frutíferos, não confiamos nos itinerários geográficos enquanto prontuário de regras para a solução de obstáculos. A cada relação, a cada situação, a cada região, devem ser elaboradas estratégias heurísticas sui generis.

Assim, nossos itinerários são poéticas do instante. Revivendo, aumentando, abrindo novos horizontes antes inimagináveis. Momentos sem antes nem depois, em que tudo no universo está em expansão. Se o patrimônio realmente possui valores excepcionais universais, para verdadeiramente compreendê-lo, precisamos agregar o 
extraordinário ao excepcional. Por isso, caminhamos no limite entre a sensação e o devaneio, numa autêntica philopsychia (ARENDT, 2016), reunindo a beleza da vida sancristovense traduzida em cores, sons e palavras. Uma força poética que dá unidade ao patrimônio.

\section{Referências}

ARENDT, H. A condição humana. Trad. Roberto Raposo. $12^{\mathrm{a}}$ edição. Rio de Janeiro: Forense Universitária, 2016.

BACHELARD, G. $O$ direito de sonhar. Trad. José Américo Motta Pessanha, Jacqueline Raas, Maria Lucia de Carvalho Monteiro e Maria Isabel. São Paulo: DIFEL, 1985.

BACHELARD, G. A poética do espaço. Trad. Remberto F. Kuhnen, Antônio da Costa e Lídia V. S. Leal. São Paulo: Nova Cultura, 1988a.

BACHELARD, G. O novo espírito científico. Trad. Remberto F. Kuhnen, Antônio da Costa e Lídia V. S. Leal. São Paulo: Nova Cultura, 1988b.

BACHELARD, G. A terra e os devaneios do repouso: ensaio sobre as imagens da intimidade. Trad. Paulo Neves. $2^{a}$ edição. São Paulo: Martins Fontes, 2003.

BACHELARD, G. A epistemologia. Trad. Fátima Lourenço Godinho e Mário Carmino Oliveira. Lisboa-PT: Edições 70, 2006.

BACHELARD, G. A poética do devaneio. Trad. Antonio Danesi. $3^{\text {a }}$ Ed. São Paulo: Editora Martins Fontes, 2009.

BACHELARD, G. A terras e os devaneios da vontade: ensaio sobre a imaginação das forças. Trad. Maria E. A. P. Galvão. $4^{a}$ ed. São Paulo: Editora Martin Fontes, 2013.

BESSE, J. Geografia e Existência a partir da obra de Eric Dardel. In: DARDEL, Eric. $O$ homem e a Terra: natureza da realidade geográfica. Trad. Werther Holzer. São Paulo: Perspectiva, 2011.

BESSE, J. Ver a Terra: seis ensaios sobre a paisagem e a geografia. Trad. Vladimir Bartalini. São Paulo: Perspectiva, 2014a.

BESSE, J. O gosto do mundo: exercícios de paisagem. Trad. Annie Cambe. Rio de Janeiro: EdUERJ, 2014b.

CERTEAU, M. de. A invenção do cotidiano: 1, Artes de fazer. Petrópolis: Vozes, 1994.

DARDEL, E. O homem e a Terra: natureza da realidade geográfica. Trad. Werther Holzer. São Paulo: Perspectiva, 2011.

DOWLING, R.; LLOYD, K.; SUCHET-PEARSON, S. Qualitative methods 1: Enriching the interview. Progress in Human Geography, 2016a, V. 40, N. 5, p. 679-686. 
DOWLING, R.; LLOYD, K.; SUCHET-PEARSON, S. Qualitative methods II: "Morethan-human" methodologies and / in praxis. Progress in Human Geography, Agosto 2016b, p. 1-9.

GRATÃO, L. H. B. O direito de sonhar em geografia: projeção bachelardiana. Revista Abordagem Gestáltica - Phenomenologica Studies, Goiânia, v. 22, n. 2, p. 148155, dez. 2016.

HEIN, J; EVANS, J; JONES, P. Mobile Methodologies: Theory, Technology and Practice. Geography Compass, V. 2, N. 5, 2008, p.1266-1285.

JASPERS, K. Introdução ao pensamento filosófico. Trad. Leonidas Hegenberg e Octanny Mota. São Paulo: Editora Cultrix, 1965.

MARANDOLA JR, E. Geografias do porvir. A fenomenologia como abertura do fazer geográfico. IN: SPOSITO, E. et al. A diversidade da geografia brasileira : escalas e dimensões da análise e da ação. Rio de Janeiro: Consequência Editora, 2016, p. 451-466.

MARANDOLA JR, E; PAULA, F. C. de; FERNANDEZ, Pablo Sebastian Moreira. A experiência do caminhar e do olhar: três percursos na Ponte Preta. RUA, Campinas, SP, v. 13, n. 1, p. 61-78, 2007.

MERRIMAN, P. Rethinking Mobile Methods. Mobilities, 9(2), p. 167-187, 2014.

NOVOA, A. Mobile ethnography: emergence, techniques and its importance to geography. Human Geographies, 9(1), 2015, p. 97-107.

PAIVA, R. de C. S. Gaston Bachelard: a imaginação na ciência, na poética e na sociologia. São Paulo: Annabule, 2005.

PRATS FERRET, M.; BAYLINA, M.; ORTIZ GUITART, A. Los lugares de la amistad y la vida cotidiana de chicas y chicos adolescentes en un barrio de Barcelona. Revista Latino-Americana de Geografia e Gênero. Ponta Grossa, v. 3, n. 2, p. 116-124, 2012.

RICOEUR, P. A memória, a história, o esquecimento. Tradução Alain François et. al. Campinas, SP: Editora da Unicamp, 2007.

SHELLER, M. e URRY, J. The new mobilities paradigm. Environment and Planning A, V. 38, N. 2, 2006, p. 207-226.

SPINNEY, J. Close encounters? Mobile methods, (post)phenomenology and affect. Cultural Geographies, Vol. 22(2), p. 231-246, 2015.

VAN MANEN, M. Researching Lived Experience: Human Science for an Action Sensitive Pedagogy. Londres: Althouse Press, 1990.

VAN MANEN, M. Writing Qualitatively, or the Demands of Writing. Qualitative Health Research, v. 16, n. 5, p. 713-722, maio, 2006.

WYLIE, J. Smoothlands: fragments/landscapes/fragments. Cultural Geographies. V. 13, N. 3, 2006, p. 458-465. 
Rafael Henrique Teixeira da Silva

Doutor em Geografia pela Universidade Estadual Paulista "Júlio de Mesquita Filho" - Rio Claro, mestre pelo Instituto de Geografia e

Ordenamento do Território (Universidade de Lisboa) e graduado em Turismo pela Universidade Federal de Ouro Preto. Atualmente é Professor Substituto do curso de Turismo da Universidade Federal do Juiz de Fora.

Universidade Federal de Juiz de Fora, São Pedro 36036900 - Juiz de Fora, MG - Brasil

E-mail: rafahts@hotmail.com

Recebido para publicação em agosto de 2018 Aprovado para publicação em dezembro de 2018 